\title{
Intonative Variety of Simple Declarative Sentences in the English Language
}

\author{
Allahverdiyeva Feride Mahammad ${ }^{1}$ \\ ${ }^{1}$ Azerbaijan University of Languages (AUL), Baku, Azerbaijan \\ Correspondence: Allahverdiyeva Feride Mahammad, Azerbaijan University of Languages (AUL), Baku, \\ Azerbaijan. E-mail: fallahverdiyeva@mail.ru
}

Received: July 22, 2015 Accepted: August 14, 2015 Online Published: September 29, 2015

doi:10.5539/ijel.v5n5p164 URL: http://dx.doi.org/10.5539/ijel.v5n5p164

\begin{abstract}
The issue of investigation of structural-syntactic and intonation types and kinds of different sentences in the language, began to be broaden since the third decade of the XX century.

The investigation of sentence intonation in the initial stage was more linked with teaching of the languages. In the later period alongside the linguists, psychologists, physics, and specialists of other branches of science also were engaged in the study of speech intonation. Up to the last years, in the carried out investigations, the main attention was paid to the formal investigation of intonation structure of communicative types of sentences. That's why only the structural-semantic analysis of communicative and derivational types of sentences was not satisfactory enough to discover their semantic contents as a whole.

But in the modern stage, study of syntax of sentence and its semantics in the plan of intonation variety, proved that the investigation of this problem is more actual than ever today. Thus, comparative study of sentence belonging to each communicative type, including the study of phono-semantic variety of simple types of declarative sentences in the English language which we carry out in a certain contextual-situational phrase, with intonative variety, bears a special importance in the modern stage. A sentence in a certain situation is used for a special purpose and receives an adequate form of intonation. The same sentence in different contexts is never expressed with the same intonation counters. It is in a certain degree subjected to different variations.
\end{abstract}

Keywords: phonetics, system, variety problem, formal aspects of intonation, syntactic function

\section{Introduction}

In learning and teaching English observations on intonation is of great importance. Each language has its own self-belonging phonetic and grammatic laws. Learning these laws scientifically plays a major role in achieving the intended goal. Thus, without learning phonetic laws, peculiar to the English language, it is impossible to master correct pronunciation habits in this language. In correct understanding, English intonation plays a great role. The fact, that the same sentence is pronounced with different intonation varieties, causes difficulty in understanding the thought.

\section{Scope of Study}

The scope of study explores the investigation of intonative varieties of structural-syntactic and phonosemantic aspects of simple declarative sentences in the English language. Different from the traditional study of intonation structure of simple declarative sentences in the English language, the study of the reasons, why the derivational kinds of this communicative type are subjected to contextual-situative variations, can be considered as an innovation of the research. Besides, in a number of cases, the syntactic contents of a sentence, thanks to variations of intonation elements, finds it exact expression. One of the aims and objectives of our approach to the research, finds its reflection in the aspect, with which we investigate the theme. The main objectives of the investigation are to determine the varieties, taking place in the structures of the models of simple declarative sentences used in certain contexts in the modern English language, and study their functional importance. English phonetist D. Jones touching upon the studied by us the problem, in the level of phonemes, used the term of "variation" and introduced this notion as the "diaphonic" change of phonemes. By the end of the $70^{\text {ies }} \mathrm{G}$. P. Torsuyev investigated the problems of constancy and variation in the phonetic structure of the word in the English phonemes. 
G. P. Torsuyev noted that constancy and variation, being one of the main peculiarities of the language structure, is linked with the inner nature of the language. Without them a language can neither exist, nor develop.

We must mention here, that G. P. Torsuyev in the same research work speaks of some functions of variation. Among them his thought on style distinctive or on stylistic function of variation, gives us serious ground that this idea can be applied in the investigation of the problem in the level of sentence intonation.

\section{Research Methodology}

For the successful realization of the goal of investigation, a number of methods and linguistic analysis means, including structural-semantic and methods of contextual analyses have been used.

\section{Variaty Nature of Speech Intonation}

Investigation of the problem of variation in the language system begins with the second half of the XX century. But research works carried out in this field, neither as to the volume nor as to the quantity was broad. Theoretically, the issue of applicability of variation to different levels of the language system at the first view can be clearly seen for the linguists. But during the practical application of the problem to the different aspects of the language and during the analysis of the language units as to the aspects, certain difficulties emerge. In the investigation of the problem, we'd like to note, first of all the activity of Professor F. Y. Veysalli. Beginning with $70^{\text {ies }}$ of the last century, he had carried out investigations, related to this field, continued his investigations both on system of phonemes and on intonational-structural levels of the language, dealing with variation, published a number of works. After F. Y. Veysalli, our another scholar D. N. Yunusov applying the variation problem on the level of syntax and intonation of the language, carried out investigations on the materials of the languages of different systems, in the comparative plan of investigation (Yunusov, 2005).

The issue of influence on the distinction of purely phonetics and intonative variations in the semantics of the sentences, in fact leads to the study of sentence phonology. During the real intercourse not any type of sentence is used in the isolated condition. A sentence in a certain instant, in a certain situation is used for a definite purpose; it is subjected to different variations. We must note here that, while speaking on tone variation, certain information has been given about its functions as well. The party, making his/her speech must take into consideration that, in order to express emotions, thoughts in his/her speech, he/she is sure to use adequate intonation. While pronouncing the words, consisting of one syllable with different tones we witness the expression of different meanings. In the modern linguistics the scientific investigation of intonation means the determination of the function of each aspect of intonation in the language.

As to the communicative function of intonation, by the utterance of any sentence, in any situation, it is possible to determine the communicative type of sentences (an interrogative, imperative, exclamatory type of sentences). So, intonation determines communicative types of sentences: They are 1) imperative sentence (expressing order, request, warning etc.): 2) declarative sentence (all kinds of declarative sentences): 3 ) interrogative sentence (all kinds of questions, general, special, repeated questions etc.): 4) exclamatory sentence (exclamation and all kind of exclamation).

If we consider the communicative function of intonation, then we shall determine the two main fields of intonation: one of them is concentration of the attention of the speaker to the most important aspect of intonation, and the other is the regulation of the mode of speech. In the first case it is important that the necessary stress should be put on the necessary syllable.

She 'arrived in 'Moscow/

Tonal stress is mostly put on the word, bearing more information.

/I have got to ask the 'child for a 'walk/

In order to focus the attention we may show at least two different ways of intonation. The chosen tone of intonation indicates the cognition of information by the unit of tone. The declarative sentences, when being expressed in low scale and low descending tone, in the contents of the sentence against the thought of the interviewer, are expressed such attitudes as, feeling of non-sympathy, coldness, indifference. For example: She could have taken my book - I hadn't known about it before.

In the English language, when the tones are used in different scales, attitudes of different colorings are expressed. We can use height and speed variations, the movement of our voice tone, can be in a very narrow frame or on the contrary, it can be in a very wide frame. Unless we use wide voice tone level, we can use different leading tones. The leading high tone (high key) may use the highest level of voice tone, the middle average tone (mid key) may use the middle part of tone level and the low leading tone (low key) may use the lower part of the voice tone. 
Even at this moment different mimics, gestures, and body movements are used. All these facts are of great importance in expressing attitude and emotions.

Intonation is determined as a complex unity of prosodic or suprasegmental speech elements. The main prosodic elements are called the components of the intonation. The main components of intonation are these: speech melody, sentence stress, speech tempo, voice tembre (Babayev, 2009).

Intonation helps to express the emotions of the speaker, the contents of the sentences, and the speaker's attitude to the contents of the uttered speech. Intonation plays an important role in the formulation of the structure of the sentences and different kinds and types of sentences. We cannot imagine a sentence without a concrete intonation. Thus, intonation is a necessary element of the sentence. Each component of sentence has a special function in the expression of a sentence.

Speech melody is a tonal component of intonation. This means musical distribution of words and sounds in the communicative speech. Human's voice is not monotonous in speech. Its tonality always keeps the changeability. Tonality in a sentence or in a sense group drawing a melodic line rises and descends. Unless tonality changes like this, each of the uttered sentence sounds monotonous, and the speech of the speaker is deprived of the important element of speech-expressiveness.

Sentence stress is a special attraction of degree of attention, by means of which the important words of the sentence are expressed by systematic intervals. Length and shortness of stressed and unstressed syllables, including the distribution of stresses in sense groups plays important role in the formulation of the rhythmic structure of the sentence. The shift of stress may also change the meaning and emphasis of the sentence.

As a rule, the more a word is important and necessary, the stronger the stress of a word is. Sentence stress establishes the basis of the rhythmic structure of the sentence.

Putting them in other words, the rhythm of English speech is formulated by the substitution of unstressed syllables and by the repetition of stressed syllables, more or less in the systematic time intervals.

While carrying out general analysis of melodic structure of non-emphatic speech in the English language, we may come to such a decision that the following factors are of special importance.

The distribution of stress in syntagm, features of musical shift of voice within the syntagm and melodic movement of voice at the end of syntagm; all these determine the semantic type of it (Zinder, 1979).

For the English language generally equally gradual descending of voice beginning from the first stressed syllable till the last one is characteristic.

Musical tone mainly changes in the stressed syllables; just from here dependence between stress and intonation arises. If a stress changes within a syntagm, then the tonal orientation also changes. Melodic line of syntagm beginning with the highest stressed syllable begins to lower in the forthcoming syllables. Thus, as if in the scale it establishes a gradual descending row. The unstressed syllables coming before the stressed syllables in a syntagm, usually are pronounced with lower tone after the stressed syllables, conditioned by being in the low flow tone which can be relatively in the higher tone.

Sentences have four types - declarative, interrogative, explanatory, and imperative sentence type, each of which is divided into the derivational types.

Declarative sentence!

This type of sentence is divided into the following semi kinds.

a) Categorical declarative sentence - expresses determination. In such sentences information does not acquire its contents at all. Such sentences are pronounced with wider diapason falling from higher or lower pitches. For ex: He 'came at, 6 .

b) Declarative sentences expressing impatience; such sentences are undertaken as the sentences expressing summons, impatience, protest.

Sometimes, they sound as creating impression of fear or self-confidence. Such kinds of sentences are generally pronounced with rise-fall. For ex: She 'sent a 'telegram 'last year.

c) Non-categorical (superficial) declarative sentences-expresses superficial, occasional attitude of the speaker to the event. For them fall-rise is characteristic. For ex: I'll wait for him. 
d) Attention drawing declarative sentences require understanding of the meaning from the listener which the speaker has not expressed. Such sentences are pronounced with fall-rise or with a rising tone in the middle. For ex: He is a good boy/probably she is/.

e) Hinting declarative sentences - are pronounced with rise-fall-rise tones. Such kind of tone makes the sentence attractive, pleasant and causes the sentence to express optimism (Brezgunova, 1968). For ex: He will return soon.

Below, examples belonging to the different kinds of scales indicating stage by stage descending scales:

1. You 'ought to lknow the 'way to say it.

2. I' asked him to 'do it for me.

3. He 'did his 'best to 'help, them.

4. We want to 'go her 'aunt, today.

5. It's 'time the children to 'go to , bed.

He used to 'play it 'very, well.

Breaking-descending stage by stage scale:

1. I 'saw them 'going to the 'museum.

2. He 'did his 'best to help the 'child.

3. He 'has to 'come 'home at six o'clock.

4. I want to 'read another 'book.

For the categorical declarative sentences, expressing firm determination, mainly low fall of melody expressing patient, cold-bloodied, indifferent attitude is characteristic. For ex: Yes, I'm ,tired. If a sentence is pronounced with a low-rise, by this time it expresses self-confidence and soothing feelings. If a sentence is pronounced by high rise, at this time it expresses the feeling of love of life, joyfulness and curiosity. For ex: I'm sure. But when it is pronounced with low stress, it expresses protest. For ex: Nobody is sure.

In the sentences in the pronunciation of which fall-rise is used, such sentences express a hint. If the fall-rise is splintered, at this time it expresses apology, sorrowfulness, caretakingness. For ex: 'Mother isn't, sure.

In the phonetic literature of the English language a number of authors, such as M. A. Antipova, 1974; V. D. Arakin, 1999; M. A. Sokolova, 1996; S.M.Babayev, 1977; F. H. Zeynalov, 2003; R. Roch, 2005, have used the term of "Melodic contour (M.C.) as "Intonation contour" (I.C.), "Intonation pattern" (I.P.), "Tone unit" (T.U.). We in our work, take advantage of using the term "Melodic contour" (M.C.). In the modern English Language six melodic contours ensuring the semantic variety of simple declarative sentences are used. In the non-emphatic declarative sentences of the English language, as a rule, Melodic contour No=1 (MK-1) is used. The simple declarative sentences expressed in this melodic contour express commonness of thought, certainty, determination, objective fact, affirmation. In the sentences of such kind tonal ending is realized by usual descending scale. For ex: 1) He 'left the 'room without a, word. 2) He wasn't , there.

MC-1 used in such kind of sentences usually expresses neutral intonation. But at the same time by MC-1 negative feelings can be expressed as well. By this time in the speech of the speaker such feelings as coldness, indifference, embarrassment, dryness, and pessimism may be expressed. Namely, the above mentioned by us the MC-1, expressing completeness, determination, certainty and so on, meanings can be added to other emotional colorings as well. For example:

\section{I 'didn't ex 'pect it from you.}

I 'don't 'like such an attitude.

\section{It's 'out of the question.}

MC-2: In this melodic contour in the simple declarative sentences of the English language, the speaker inspires colourful feelings as soothing down, feeling of easiness, self-confidence, non importance of the problem etc. On the other hand, in many cases it is intended to encourage, not give trouble, to please the listener. In the sentences of such kind the final of the sentence is pronounced with usual rising tone. For ex: 'Never , mind. It's 'all right. There is nothing to , worry about.

This melodic contour is also characteristic for the utterance of non-terminal syntagns of not coming in the end. At this time in the syntagm rising tone is used and it states the continuation of the thought. 
But variant "a" of melodic contour (MC-3) states the continuation of the speech as to the theme and this intonation contour expresses negative feelings such as non-tolerance, criticism, hurt etc. Sentences of such kind are used in the contexts of interview and discourses and show themselves as answers to the given questions. The answers given to the reactions possess a rising tonal ending. For example: I think her answers are correct. - It is definitely not the correct answer.

MC-3. This melodic contour is widely used in the spoken language. This contour is often understood as the attitudes among the persons. Conversation sounds very vivid and interesting, the negotiating parties willingly express their attitudes to the discussed problem, but sometimes on the contrary, they express their serious dissatisfaction. MC-3 being realized by stage by stage scale expresses soft and mild attitude. For example: It's always 'better to learn. We 'haven't known him for years.

MC-4. This melodic contour, while being used in simple declarative sentences, sounds like an echo and as repetition of the uttered word by the listener in the form as it is. At this time, though a stimulus is in the affirmative or interrogative form, reaction sounds as a question. For example: She is reading - 'She is 'reading?, I 'don't like it - I don't , like it.

MC-5. The fifth melodic contour usually is expressed in the sentences possessing covert meaning (implication). In other words, the issue which the speaker intends to express is entirely clear, both to the speaker and the listener, because this clearness emerges from the existing situation, from the theme of the conversation, but the verbal expression of implication is not demanded. For example: I don't ask you to 'come , today (but tomorrow, soon, next week, in two days etc.).

The sentences which express implication usually possess rising final.

MC-5 model possesses another emphatic type. In such sentences the following typical attitudes are very briefly, in the verbal form expressed by compound tones:

a) only when correcting the interlocuter gently;

b) while unwillingly accepting the offer;

c) somehow rejecting something in the mode of self-difference;

d) while expressing offence from someone;

e) while hesitating

For example:

1. There were ten sheep in the yard - 'Eleven.

2. I wouldn't go there - I 'wouldn't.

3. He won't do anything - 'He 'will.

\section{I think you have known about it - Not 'exactly.}

MC-6. During the use of this type of melodic contour tonal load transfers to the strong falling tone. By this time certainty and completeness of meaning is added by a kind of warm attitude, admiration, sarcasm, and anger, thus in conformity with the created situation, emotions, either negative or positive emotions are expressed.

The speaker himself/herself is very much impressed. For ex:

May I take this book? - Certainly, Surely.

Will you help me? - Willingly, Gladly.

-Have you had a good time? - A 'marvelous time.

-Wasn't it a good film? - 'Very good.

\section{Conclusion}

The results gained from the discussed issues in the separately-taken branches of the study can be generalized as follows:

Variation is one of the natural, self-belonging features of language system. It operates in all the levels of language.

The intonative variation of language units is always intended in comparison with the notion of constancy (as variant and invariant attitudes). 
From this view point, for the determination of, in which level of the language variation bears the process-creating function and in which one, it bears the meaning of distinctive function, we think it necessary to carry out the following comparison.

1. Variety in the level of phonemes mainly represents as phonetic, more exactly saying, as allophonic variety. In this level the variation which takes place, creates mechanisms of phonetic processes such as assimilation, dissimilation accommodation, reduction, elision, epenthesis etc. On the background of such processes favorable condition is established for national accent of English-speaking people, national accentuation and for the easiness of speech.

2. When approaching the problem in the sentence level it is clearly observed that in the English language intonation variation plays both the roles of relevancy and non-relevancy.

In the functional plan, sentence intonation, thanks to its quick features of variation is able to create a number of semantic distinctions in the structural-syntactic units.

In this respect we have to note that, in the traditional grammar the communicative types of sentences were called as "the types of sentences as to their intonation". Namely, variation, taking place in the intonation contour in the process of communication serves to determine the communicative type of the sentence. Putting it in other words, we can say that by the intonation variation, one communicative type is transferred to another communicative type. (For example in the daily English speech the affirmative sentence "you're all right?" used in the intonative form bears the form of question "You are all right?")

Within the frame of intonation variation of a simple declarative sentence, having the same syntactic structure, in the explicit plan, and being sounded categorically expressing a resolute sentence, in the implicit plan, it sounds like expressing non-categorical incompleteness, loss of confidence, doubt etc. semantic colorings. In the first case, the declarative sentence is pronounced with rising tone, in the second case it is pronounced with fall-rise.

In the normative speech plan the main structural-syntactic and structural semantic functions of intonation variation of the simple declarative sentence can be determined as follows:

1. A sentence forming function.

2. A function supplying the sentence border.

3. A distinctive function.

4. A function to express attitude.

The first function: The word composition and its grammatic structure possess an inseperatable unity and is of a certain form. The form of intonation ensures the expression of affirmative, negative or interrogative, exclamatory, imperative meanings of the sentences.

The second function: The final limit of the sentence is determined by the direction of the tonal level in the last nuclear syllable of the sentence and by the proper pause. This process can also be observed in the middle syntagms of the sentence. At this time, sometimes pause, can be substituted by nuclear tone.

The third function: The distinctive function of intonation manifests itself on the basis of such a fact: The distinctive types of sentences from the communicative view point, can only be determined by means of intonative variations. This function creates background for any communicative type and its derivational types to express different syntactic-semantic meaning colourings.

The fourth function: Determines the air of the speaker, his/her attitude to the situation, including the listeners attitudes taking place in this situation. All these meanings are linked with variations, taking place in the intonation contours.

Variation features of sentence intonation in the normative speech, as we have mentioned above, basically serve to express syntactic-semantic meanings of communicative types and kinds of simple declarative sentences.

But during the emphatic speech, the extremely rich meaning colourings of different sentences and expressions, their expressive-emotional, logical-predicative and other functions are conditioned by more emphasized and intensive functions, taking place in the intonation variations:

1) In order to make simple declarative sentences, linked with special contextual situation, more emphatic, strengthening emphasis is used. A sentence is formulated by the widening of the voice diapason and by strengthening of the sentence stress. 
2) The determination of logical predicative centre in the simple declarative sentences, is realized by the use of tonal variant, increasing the logical stress in the sentence.

3) Confrontation of a state or action expressed in one part of the sentence with the same cases expressed in the other part of the sentence is called contrastive-comparative function of emphatic intonation (For example: $I$ didn't 'tell him to go there). This is called contrastive function of logical emphasis.

\section{References}

Antipova, A. M. (1979). The system of English speech intonation.

Antipova, A. M. (1971). Intonation of English.

Babayev, S. M. (1966). Intonation features of simple declarative sentences with gerund in Modern Azerbaijani (Experimental phonetic research in comparison of English). Bak1.

Brisgunova, E. A. (1968). Practical Phonetics and Intonation of Russian.

Jones, D. (1957). An outline of English phonetics. Cambridge.

Roach, P. (2005). English phonetics and phonology. Cambridge.

Smirnitskiy, A. I. (1957). Syntax of English.

Sokolova, M. A. et al. (1984). Practical phonetics of the English language.

Yunusov, D. (2007). Constancy and variety of complex syntactic units in languages of different systems. Istanbul.

Yunusov, D. N. (1987). Intonation structure of a complex sentence with the conjunction "that" and without it in modern English.

Zeynalov, F. H. (1974). Stress and its connection with fonetic problems.

Zeyrialov, F. H. (2003). An introduction to the English practical phonetics. Book 1. Baku.

Zinder, L. R. (1979). General Phonetics.

\section{Copyrights}

Copyright for this article is retained by the author(s), with first publication rights granted to the journal.

This is an open-access article distributed under the terms and conditions of the Creative Commons Attribution license (http://creativecommons.org/licenses/by/3.0/). 